grandfather's brother and one of her cousins, were operated on in Glasgow, several of them by the late Mr. Henry E. Clark. In all the cases the cataract came on between the ages of 13 and 18 years, and previous to this the vision was good. After operation, and with the usual corrections, they seem to have obtained good vision. The cases that we have seen in the early stages presented opaque rádiating spokes like ordinary senile cataract. Both eyes are usually affected. Mrs. F. states that her family and her relations are all healthy people.

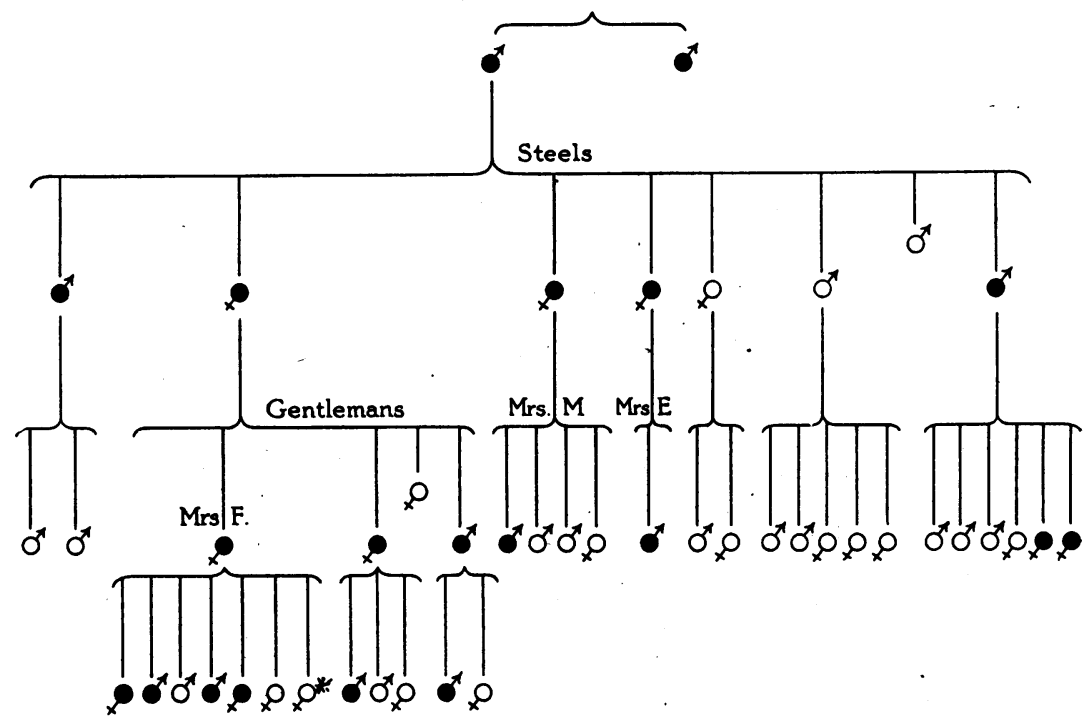

*NotE.-Since the above was written it has been found that Mrs F.'s youngest daughter has cataract. - J.R.

\title{
A GALILEAN ADAPTER
}

BY

\author{
H. GRIMSDALE, \\ LONDON.
}

IN The Ophthalmoscope for 1911, on page 41 et seq., there is an account of telescopic spectacles which probably everyone who has tested them has found of very varying utility. Some patients rejected them; others found them of great service, and it was not possible to foretell their value in any given case. This uncertainty, together with their considerable cost, was sufficient to make one chary of ordering them, and yet on occasion they gave great help. 
In my personal experience, I have found few patients who appreciate the larger image for distance; in most cases, where it is desired to have a large image when reading, it can be obtained by shortening the reading distance, but there are a few people for whom this is very inconvenient ; such, for example, are musicians, who must read at a considerable distance, and those whose professions entail much reading aloud, when the face must not be buried in the book. To these the spectacles are often of great assistance.

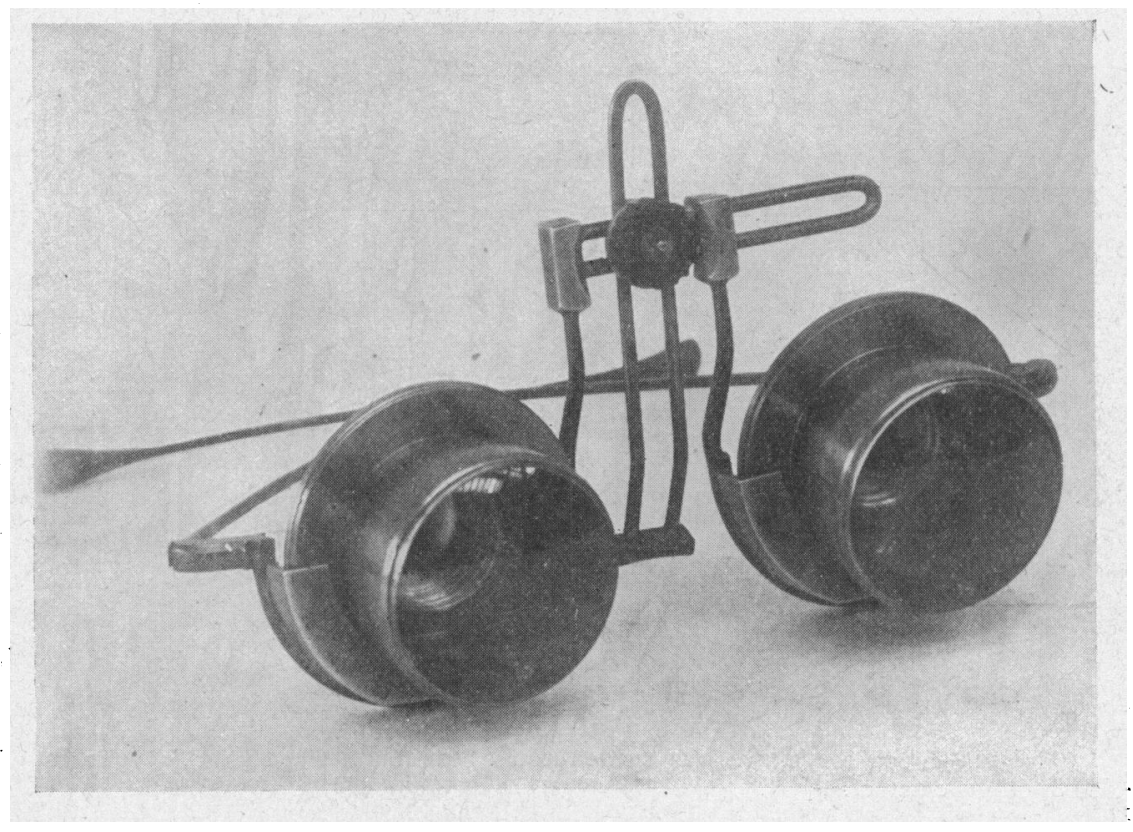

This adapter, which has been made by Mir. Coppock, of Messrs. Leon and Co., 7, Piccadilly Arcade, allows the surgeon to make a trial so as to gauge its probable value to any patient. It can be placed in the front cell of a trial frame and worn with the patient's static correction. The combination chosen allows an eye made emmetropic, to read at a distance of about 16 inches and gives a magnification of 1.5 .

If it be desired to try the effect for distance, a concave lens of about - 4.0 D. must be added to the "distant" correction; the exact strength varies a little with the distance between the adapter and the added lens. 